\title{
Employment and exchange rates: the role of openness and technology*
}

\author{
Fernando Alexandre ${ }^{\dagger} \quad$ Pedro Bação $\quad$ João Cerejeira ${ }^{\S}$ \\ Miguel Portela
}

26th October 2010

\begin{abstract}
Real exchange rate movements are important drivers of the reallocation of resources between sectors of the economy. Economic theory suggests that the impact of exchange rates should vary with the degree of exposure to international competition and with the technology level. We show that both the degree of openness and the technology level mediate the impact of exchange rate movements on labour market developments. According to our estimations, whereas employment in hightechnology sectors seems to be relatively immune to changes in real exchange rates, these appear to have sizable and significant effects on highly open low-technology sectors. The analysis of job flows suggests that the impact of exchange rates on these sectors occurs through employment destruction.
\end{abstract}

Keywords: exchange rates, international trade, job flows.

JEL-codes: J23, F16, F41

${ }^{*}$ We are grateful for insightful comments and suggestions from Nicolas Berman, Delfim Neto, Ana Rute Cardoso, Miguel Lebre de Freitas, João Amador, Colin Cameron and other participants at NIPE's seminar, and at the conferences "International Workshop on Firm and Product Heterogeneity in International Trade", held in Brussels, "10 years of the euro: adjustment in capital and labour markets" held at University of Minho, Royal Economic Society Conference held at University of Surrey and Portuguese Economic Journal Conference held at University of Algarve. We also thank the editor and two anonymous referees for valuable comments.

${ }^{\dagger}$ Corresponding author: Escola de Economia e Gestão and NIPE, University of Minho, Campus de Gualtar, 4710-057 Braga, Portugal. Email: falex@eeg.uminho.pt.

¥University of Coimbra and GEMF. Email: pmab@fe.uc.pt.

$\S$ University of Minho and NIPE. Email: jccsilva@eeg.uminho.pt.

『University of Minho, NIPE and IZA. Email: mangelo@eeg.uminho.pt. 


\section{Introduction}

In recent decades, employment in manufacturing has been declining in developed countries - between 1988 and 2006 it decreased by approximately 40 per cent and 20 per cent in the UK and in the USA, respectively. In 2006, manufacturing employment represented approximately 10 per cent of the workforce in those countries. ${ }^{1}$ Skill-biased technological change - see, for example, Bound and Johnson (1992) or Machin and Van Reenen (1998) - and globalization - see, for example, Wood $(1994,1998)$ - have been the leading explanations for the observed decline in manufacturing employment and, in particular, for the decrease in the demand for unskilled relative to skilled workers. Analyses of the effect on manufacturing of the reduction in trade barriers in recent years suggest that competition from emerging countries, namely China and India, has had a negative impact on manufacturing employment in developed countries - see, for example, Bernard et al. $(2006)^{2}{ }^{2}$

Another strand of the literature has been focusing on the impact of movements in real exchange rates on manufacturing labour markets. Economic theory suggests that changes in real exchange rates may have an impact on the reallocation of resources between sectors of the economy as they reflect changes in relative prices of domestic and foreign goods. $^{3}$ Branson and Love (1988), using data for the 70 s and 80 s for the US, were among the first to conclude that real exchange rate movements had a strong impact on manufacturing employment. Namely, they found that the appreciation of the dollar in the first half of the 80s had a strong negative effect on employment. A similar result was found by Revenga (1992), for the period 1977-1987, who concluded that real exchange rate movements had sizable effects on employment and a smaller, but significant, effect on US manufacturing wages. Burgess and Knetter (1998) evaluated the impact of real exchange rate movements on employment at the industry level for the G-7 countries and showed that real appreciations were associated with declines in manufacturing employment in most cases. In particular, these authors conclude that employment growth in the US, UK, Canada and Italy is more sensitive to exchange rates than in Germany, Japan and France. In the same vein, Gourinchas (1999) and Klein et al. (2003a) found that real exchange rates have a significant impact on job reallocation.

These papers, among others, have emphasized the role of openness in the determination of the impact of exchange rates on economic activity. As expected, the conclusion of these studies was that trading sectors and, in particular, sectors more exposed to international

\footnotetext{
${ }^{1}$ Data from the OECD STAN database available at www.oecd.org/sti/stan/.

${ }^{2}$ Auer and Fischer (2008), in a related paper, conclude that trade with low-income countries has had a significant impact on U.S. industry productivity and prices.

${ }^{3}$ The effect on firms' competitiveness of an exchange rate movement may be likened to that of a change in tariffs - see Feenstra (1989).
} 
competition are more affected by exchange rate movements.

Recent studies in international trade theory, following Melitz (2003), have been focusing on the relation between international trade and productivity. Namely, these authors have concluded that firms' reaction to international competition differs sharply across different levels of productivity. A recent study by Berman et al. (2009) looks at the implications of the new literature on trade for the adjustment of export firms to exchange rate movements. They show that high and low performance (measured in terms of productivity or value added per worker) firms react very differently to exchange rate depreciations, that is, heterogeneity in productivity across firms results in differentiated responses to exchange rate depreciations. According to their theoretical and empirical results, high performance firms raise their markup instead of exported quantities when there is an exchange rate depreciation, whereas low performance firms follow the opposite strategy. Although Berman et al. (2009) do not explore them, their model has also implications for the behaviour of labour demand. In Alexandre et al. (2009a) we derive the exchange rate elasticity of labour demand as a function of productivity. There we show that both productivity and competition affect the reaction of employment to exchange rate movements and that, therefore, the effect of exchange rate movements on labour demand should vary across different combinations of degrees of trade openness and levels of productivity. Namely, the model implies that very open low-productivity firms should be the most affected by exchange rate movements, whereas less open and high-productivity firms should be the least affected by changes in exchange rates.

In this paper we study these links between employment, exchange rates, openness and productivity using Portuguese data. We focus our analysis on the effect of real exchange rate movements on 20 manufacturing sectors, which we divide into low and high technology sectors. Low technology sectors correspond to low and medium-low technology sectors in the OECD technology classification, whereas high technology sectors include medium-high and high technology sectors according to the OECD classification. ${ }^{4}$ We use this division as a proxy for productivity. This is supported by evidence provided in Alexandre et al. (2010). In our analysis we consider the period 1988-2006, during which the Portuguese manufacturing labour force followed the declining trend described above for industrialized countries: using the STAN database, we found that in 2006 manufacturing sectors accounted for 18.1 per cent of total employment, down from 24.4 per cent in 1988. Over this period, total employment in these sectors declined 15 per

\footnotetext{
${ }^{4}$ The OECD classification system divides sectors into four classes of technology - low, medium-low, medium-high and high - ranked according to indicators of technology intensity based on R\&D expenditures (OECD, 2005). For a list of the sectors used in our study, grouped by technology level, see Table 3 in the Appendix.
} 
cent, representing a loss of almost 160000 jobs. ${ }^{5}$ This reduction of manufacturing sectors' share in the labour force partly reflects the deindustrialization trend, mentioned above, that has affected advanced countries since the 1980s. However, it is also important to analyse sectoral trends. There are clear decreasing trends in employment in low and medium-low technology sectors. Low and medium-low technology sectors accounted for over 80 per cent of total manufacturing employment: 86.6 per cent in 1988 and 82.4 per cent in 2006. These sectors accounted for all the manufacturing jobs lost in this period. Medium-high and high technology sectors increased the number of jobs slightly over the same period. Meanwhile, the degree of openness has increased for all technology levels and the real effective exchange rate appreciated by more than 20 per cent. The bulk of this appreciation took place between 1988 and 1992. This period was followed by marginal variations in the real exchange rate until the Portuguese escudo joined the euro. The period since then has again been characterized by an appreciation of approximately 7 per cent.

The timing of those changes suggests that analysis of the Portuguese experience may improve the understanding of the role of differences in trade openness and technology level across sectors in the determination of the effects of exchange rate movements on economic activity. In fact, Portugal's adoption of the euro was viewed as a means to, among other things, bring about a structural shock that would force Portuguese companies to upgrade in order to be able to face increased foreign competition, since the devaluation weapon would be surrendered upon introduction of the euro - see, for example, Lopes (2008). Around the time the decision was taken, fears were voiced concerning the impact of the single currency on Portuguese manufacturing employment, contradicting that benign view. The macroeconomic performance since the introduction of the euro has been disappointing. The European Commission in its assessment of the first decade of the euro (European Commission, 2008), contrasting the economic performance of Spain and Portugal, suggests as a tentative explanation the larger nominal devaluation of the peseta: the Spanish currency was devaluated by around 30 per cent in the 1990s before adopting the euro, while the Portuguese escudo was devaluated by 12 per cent. In this paper we attempt to gain a better understanding of the effects of exchange rate movements on labour markets. Our subject matter will be the Portuguese economy, which, given the facts described above, has been viewed as an important case study for prospective EU/eurozone members. ${ }^{6}$

In our analysis, we focus on the effects on employment growth and job flows. Foreshadowing our conclusions, our estimates suggest that exchange rate movements have a

\footnotetext{
${ }^{5}$ However, the decrease manufacturing employment was accompanied by a 15 per cent increase in the labour force.

${ }^{6}$ For an earlier assessment of the Portuguese economy during the period 1960-2004, see Lains (2008).
} 
larger impact on very open and low-technology industries. On the other hand, our estimates seem to indicate that open economies specialised in high-technology sectors are more insulated from disturbances in exchange rates.

The remainder of the paper is organized as follows. Section 2 begins with a description of the data employed and of our empirical strategy. This is followed, in subsection 2.2, by the econometric analysis of a set of models that attempt to evaluate the role of openness and technology in the determination of the impact of real exchange rates on employment. We present a similar analysis for job flows in subsection 2.3. Section 3 concludes.

\section{Exchange rates and the labour market: empirical analysis}

\subsection{Econometric strategy}

In order to disentangle the relevance of trade openness and productivity to the effects of exchange rate movements on employment we implemented a three-step strategy. First, we estimate benchmark regressions, like those estimated in Campa and Goldberg (2001) and Klein et al. (2003a), among others, where we include only the exchange rate and its interaction with openness. In a second step we allow the technology level to influence the impact on employment of both the exchange rate and trade openness. Finally, we introduce additional flexibility by estimating the model separately for each technology level. Throughout the analysis we divide our sample in high technology sectors (high and medium-high technology level, according to the OECD classification) and low technology sectors (low and medium-low technology level, according to the OECD classification).

Data on Portuguese international trade comes from OECD STAN bilateral trade database. We focus on 20 manufacturing sectors, as they are more exposed to foreign trade. The sectors were selected to match the International Standard Industrial Classification of all economic activities, Revision 3 (ISIC Rev. 3). Data on employment comes from the "Quadros de Pessoal" dataset provided by the Portuguese Ministry of Labour and Social Solidarity (Portugal, MSSE, 1988-2006). This dataset is based on a compulsory survey that matches all firms and establishments with at least one employee with their workers. In 1988, it included 122,774 firms and 1,996,933 workers, covering 44.6 per cent of total employment. In 2006, it included 344,024 firms and 3,099,513 workers, covering 60.5 per cent of total employment.

The baseline specification for the econometric analysis is as follows: 


$$
\begin{aligned}
\Delta y_{j t} & =\beta_{0}+\beta_{1} \Delta \text { ExRate }_{j, t-1}+\beta_{2} \Delta \text { ExRate }_{j, t-1} \times \text { Open }_{j, t-1} \\
& +\beta_{1 L} \Delta \text { ExRate }_{j, t-1} \times \text { Low }_{j}+\beta_{2 L} \Delta \text { ExRate }_{j, t-1} \times \text { Open }_{j, t-1} \times \text { Low }_{j} \\
& +\beta_{3} \Delta \text { ShareImp }_{j, t-1}+\beta_{4} \text { Open }_{j, t-1}+\lambda_{t}+\theta_{j}+\varepsilon_{j t},
\end{aligned}
$$

where $\Delta$ denotes first-difference, $j$ refers to sectors and $t$ indexes years. The dependent variables $y_{j t}$ may be either employment (measured as total workers), job creation, job destruction or gross reallocation (these three variables are defined at the sector level - see section 2.3). ExRate Ext-1 $_{j}$ is the lagged real effective exchange rate for sector $j$, where the bilateral weights are given by total trade (exports plus imports) shares. ${ }^{7}$ The exchange rate index is defined such that an increase of the index is a depreciation of the currency. This exchange rate is smoothed by the Hodrick-Prescott filter, which filters out the transitory component of the exchange rate. ${ }^{8}$ This is the usual procedure in the literature - see, for example, Campa and Goldberg (2001) - as firms, in the presence of hiring and firing costs, are expected to react only to permanent exchange rate variations.

As discussed above, the effects of exchange rates on employment should differ according to the degree of trade openness. Therefore, we include in equation (1) an interaction term for the exchange rate and our measure of trade openness, $O p e n_{j, t-1}$, which is the ratio of exports plus imports to exports plus imports plus gross output. Similarly, we include the interaction of the exchange rate with a dummy variable indicating low technology sectors, $L_{o w}$. For additional flexibility of the model's functional form, we also extend this interaction to the sectors' trade openness.

Recent studies have concluded that competition from emerging countries has had a significant impact on manufacturing sectors in industrialized countries - see, for example, Auer and Fischer (2008). The competition from emerging countries may affect Portuguese firms either directly, through their penetration in the domestic market, or indirectly, by reducing exporting firms' external demand. Therefore, to account for competitors from emerging countries, ${ }^{9}$ we include in our regressions the variable Share $\operatorname{Imp}_{j, t-1}$, which is

\footnotetext{
${ }^{7}$ When the importance of trading partners varies across sectors, sector-specific exchange rates may be more informative than aggregate exchange rate indexes as indicators of industries' competitiveness - see, for example, Goldberg (2004), Campa and Goldberg (2001) for the US and Gourinchas (1999) for France and Alexandre et al. (2009b) for the Portuguese economy. Data for exchange rates were computed in Alexandre et al. (2009b) and are available at http://www3.eeg.uminho.pt/economia/nipe/docs/2009/DATA_NIPE_WP_13_2009.xls.

${ }^{8}$ Following Ravn and Uhlig (2002), the smoothing parameter was set equal to 6.25.

${ }^{9}$ The set of emerging countries includes Bulgaria, Czech Republic, Estonia, Hungary, Latvia, Litunia, Poland, Romania, Slovak Republic, Slovenia, China, Chinese Taipei, Hong Kong, India, Indonesia, Malasya, Philippines, Singapore, Thailand.
} 
the share of these countries in sector $j$ OECD countries' imports. ${ }^{10}$ Summary statistics for the variables described above are available in Table 4 in the Appendix.

The model also includes a set of time dummies, $\lambda_{t}$, in order to control for any common aggregate time varying shocks that are potentially correlated with exchange rates, ${ }^{11}$ and a set of sectoral dummies $\theta_{j}$. Since we specify a model in first-differences, these dummies account for sector-specific trends. Finally, $\varepsilon_{j t}$ is a white noise error term. All variables are in real terms. The model is estimated by OLS, with robust standard errors allowing for within-sector correlation. ${ }^{12}$

\subsection{Results: exchange rates and employment}

Table 1 summarizes the results for the model specified in equation (1). The first two columns of Table 1 show the results for the effect of real exchange rates using the benchmark regression, ALL. Columns (3) and (4), under FULL, extend this specification by including the level of technology. The next two sets of regressions, columns (5) and (6), and columns (7) and (8), respectively, implement the estimation of the model for the high-technology sectors, HighTech, and low-technology sectors, LowTech. Even-numbered columns include sectoral dummies. ${ }^{13}$

In the top panel of Table 1 we show the estimated coefficients and their standard errors. In order to assess the roles of openness and technology in the sensitivity of employment to exchange rate movements we compute exchange rate elasticities of employment for different degrees of trade openness, which are shown in the second part of the table. In our analysis we consider a low, a median and a high degree of openness. We measure these as three percentiles of the degree of openness: 10, 50 and 90.

Looking at the benchmark regressions (ALL), which do not control for the technology level, we observe that the interaction term between the exchange and openness is statistically significant and positive. This result seems to corroborate the results of Klein et al. (2003a), that is, the effect of the exchange rate on employment is magnified by trade

\footnotetext{
${ }^{10}$ Alternatively, we have included the share of non-OECD imports in Portuguese manufacturing sectors. However, this was not statistically significant in explaining employment variations. Results are available form the authors upon request.

${ }^{11}$ Since we use time dummies to account for aggregate shocks, our identification strategy relies mainly on the inclusion of the sectoral exchange rates. Other sources of heterogeneity are variations in overall level of trade exposure $O_{p e n} n_{j-1}$. An alternative to the use of time dummies would be to introduce controls such as real GDP, unit labour costs, real interest rate and the oil price. However, their coefficients are not statistically significant in most of our specifications and our conclusions would remain.

${ }^{12}$ An obvious alternative would be to estimate a dynamic panel data model, using adequate instrumental variables estimators. However, the inclusion of the lagged dependent variable as an additional regressor produced a statistically non-significant coefficient.

${ }^{13}$ Table 4 in the Appendix provides descriptive statistics per sector for the main variables used in our analysis.
} 
openness. $^{14}$

Computing the exchange rate elasticity of employment at different openness percentiles, its magnitude does increase, going from 0.4 to 2.1 (column 2). However, these estimated elasticities are not statistically different from zero.

Nevertheless, the benchmark model ignores Berman et al. (2009) view that productivity influences the exchange rate elasticity of employment. It is to this alternative that we now turn. Specification FULL (columns 3 and 4 in Table 1) introduces the dummy variable Low in the model via additional interactions: (i) $\Delta$ ExRate $_{j, t-1} \times$ Low $_{j}$; (ii) $\Delta$ Ex Rate $_{j, t-1} \times$ Open $_{j, t-1} \times$ Low $_{j}$. These interactions aim at evaluating the importance of trade openness and technology level for the impact of exchange rate movements on employment. Our results, shown in columns (3) and (4), FULL, indicate that for a high degree of openness, percentile 90, employment in high-technology sectors does not seem to be sensitive to exchange rate movements (the estimated elasticity is 1.5 , but not statistically different from zero). However, for low-technology sectors a 1 per cent depreciation of the exchange rate is associated with a 4.8 per cent increase in employment. Moreover, the F-statistic of 5.4 indicates that exchange rate elasticity is different for low- and hightechnology sectors. Even though the sign and the magnitude of the elasticities are as expected when the specification includes sectoral dummies - column (4) -, its statistical significance does not hold.

This result appears to support the implications of the model in Alexandre et al. (2009a), that is, that the level of technology plays a role in the transmission of exchange rate movements to labour markets, and motivates further estimations. Namely, we separate the sample between low- and high-technology sectors for the estimation of equation (1). What stands out in columns (5) and (6), HighTech - high-technology sectors -, is the negative exchange rate elasticity of employment for the less open sectors (percentile 10). For higher degrees of openness the absolute magnitude of the elasticity decreases and becomes statistically insignificant. From a theoretical perspective this result may be explained by the effect of the exchange rate variation on the price of imported inputs, that is, firms that rely heavily on imported inputs may have their competitiveness negatively affected by a depreciation of the exchange rate. Empirically we cannot test this hypothesis as we do not have data on firms' foreign trade. ${ }^{15}$

Proceeding to columns (7) and (8), LowTech - low-technology industries -, we find that a depreciation increases employment growth, and that this effect is larger when the degree of openness is higher. As we shift our attention to low-technology sectors with a

\footnotetext{
${ }^{14}$ Klein et al. (2003a) measure industry openness using a five-year moving average of the ratio of total trade to total market sales.

${ }^{15}$ For an empirical analysis of the effect of exchange rate movements on employment, through its effect on the cost of imported inputs, see, for example, Ekholm, Moxnes and Ulltveit-Moe (2008).
} 
higher degree of exposure to external innovations, the impact of exchange rate movements on employment growth becomes clear-cut in terms of economic and statistical significance. Sectors with a high openness degree, that is, in percentile 90, present an exchange rate elasticity of employment of 4.9: a 1 per cent depreciation induces a 4.9 per cent increase in low-technology sectors' employment. This estimated elasticity is larger than those reported in the literature for other countries, namely for the US (Revenga, 1992, Campa and Goldberg, 2001) and France (Gourinchas, 1998). This difference may be explained by differences in the composition of low-technology sectors and by specific characteristics of the sectors that belong to that category, which are not captured by the OECD technology classification. This is an issue that deserves further research.

The specification of our regressions controls for the impact of emerging countries competition on domestic employment. The coefficients estimated for the share of emerging countries in sector $j$ OECD countries' imports show that this competition has had a negative and statistically significant impact on employment growth. The statistical significance of this effect is independent of the technology level. However, the impact of the competition of emerging countries' imports seems to be larger for high-technology sectors (HighTech regressions in Table 1). For example, from the analysis of column (8) we conclude that for low-technology sectors a 1 percentage point increase in the share of emerging countries decreases employment by 1.4 per cent. These results may be explained by the data used in our estimations. In fact, in our data the emerging countries group includes China, other Asian countries and Central and Eastern European countries. Although the competition from China is expected to affect mainly low-tech sectors, it has been shown (see Amador et al., 2009) that competition from Central and Eastern European countries has affected significantly Portuguese medium-high and high technology sectors.

As a robustness check, we estimated equation (1) using hours ${ }^{16}$ as the dependent variable instead of employment. The results are presented in Alexandre et al. (2009a) and confirm the results found in the estimates for employment growth (Table 1). Another robustness check was the application of the Chow test. Given that the data includes pre- and post-euro periods the break date is 1999. The results in Table 1 only reject the null hypothesis of no break for the LowTech specifications. We estimated separate regressions for the pre- and post-euro periods and the patterns exhibited by the exchange rate elasticity match the description given above. Finally, we have also experimented introducing dummies to represent different degrees of openness. Namely, we introduced a dummy for sectors with openness between the 33 and 66 percentiles and another dummy for sectors with openness above the 66 percentile. This did not change our conclusions regarding the behaviour of the exchange rate elasticity.

\footnotetext{
${ }^{16}$ Data for hours is not available for 1990 and 2001.
} 


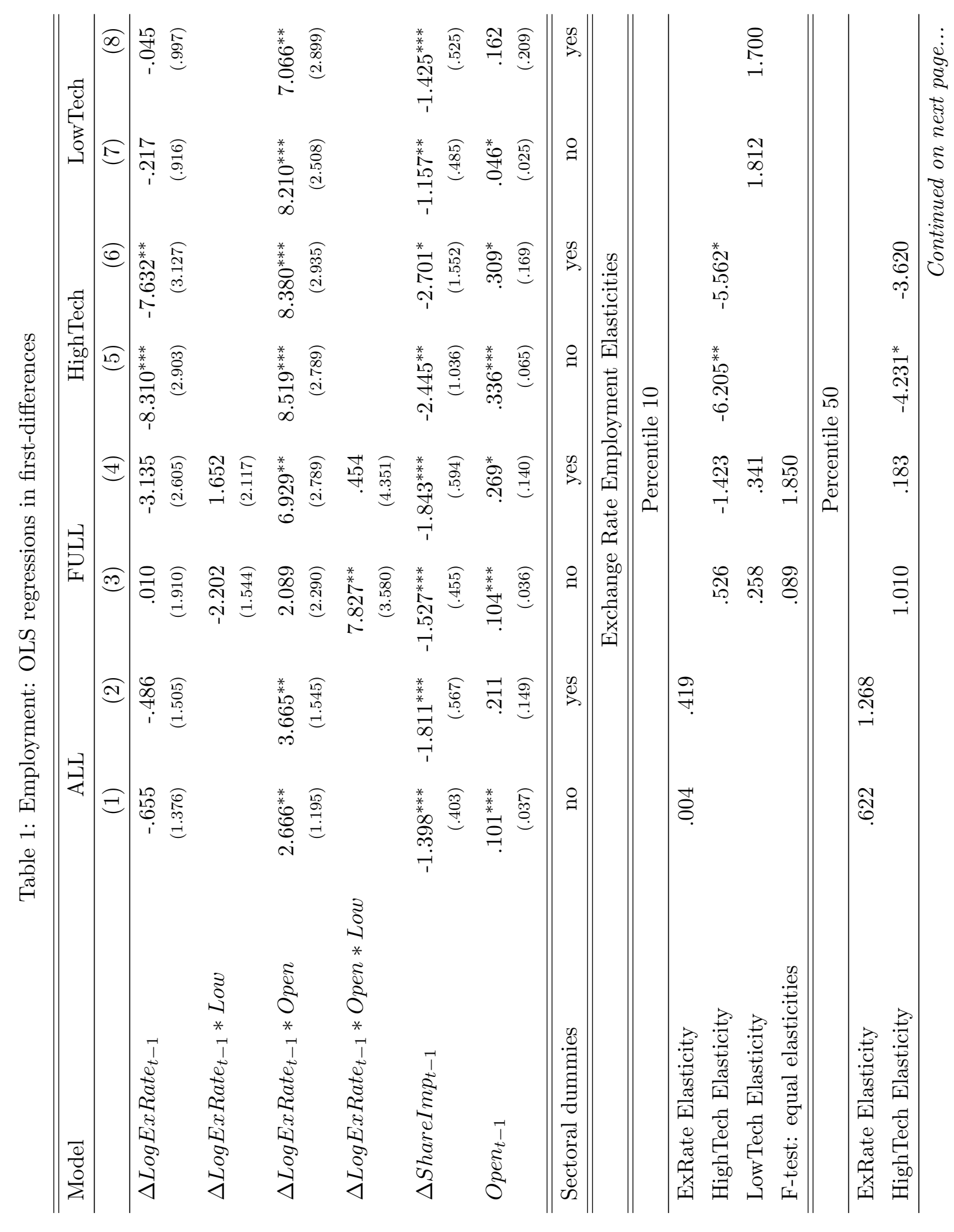




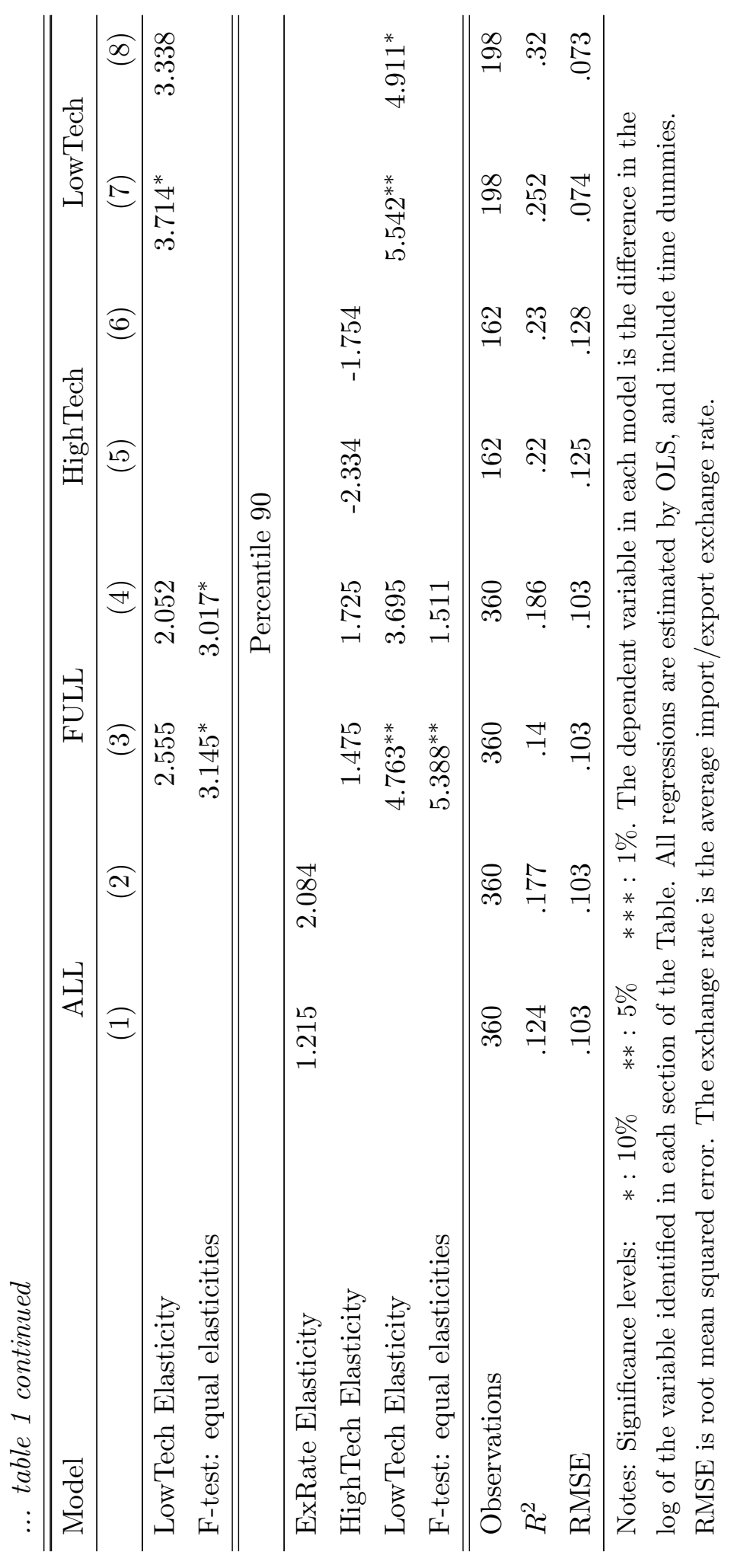




\subsection{Results: exchange rates and job flows}

In this section, we evaluate the impact of exchange rate movements on job creation, job destruction and job reallocation. The analysis of job flows may contribute to a better understanding of the role of openness and technology level on the effect of exchange rate movements on employment growth. Indeed, gross creation and destruction flows are usually one order of magnitude higher that net ones: the same net variation in jobs might be in principle generated by different combination of creation and destruction with diverse welfare implications. As summarized by Klein, Schuh and Triest (2003b), labour adjustment costs arise with hiring and firing costs, particularly training, in case of job creation, and loss of firm-specific human capital, in case of job destruction. Therefore, measures of job creation and destruction provide additional information on the dynamics of labour markets. (Davis, Haltiwanger and Schuh, 1996).

The rate of job creation in sector $j$, in year $t, C_{j t}$, and the rate of job destruction, $D_{j t}$, are defined as

$$
C_{j t}=\frac{\sum_{i \in j^{+}} \Delta E_{i t}}{\frac{1}{2}\left(E_{j, t-1}+E_{j, t}\right)}
$$

and

$$
D_{j t}=\frac{\sum_{i \in j^{-}}\left|\Delta E_{i t}\right|}{\frac{1}{2}\left(E_{j, t-1}+E_{j, t}\right)}
$$

where $j^{+}$is the set of firms of sector $j$ for which $\Delta E_{i t}>0, j^{-}$is the set of firms of sector $j$ for which $\Delta E_{i t}<0$ and $E_{j, t}$ is sector $j$ employment level at year $t$. Job reallocation is given by the sum of job creation and job destruction rates: $R_{j t}=C_{j t}+D_{j t}$.

In this section we estimate equation (1) using as dependent variables $C_{j t}, D_{j t}$, and $R_{j t}$ as defined above. We followed the strategy described in Section 2.1. In Table 2 we present the results for the creation rate and the destruction rate, for the HighTech and the LowTech specifications only - the results for the other specifications are available in Alexandre et al. (2009a). As for the creation rate, it should be noticed the negative exchange rate elasticity of job creation for high technology sectors. This result may be related to the negative elasticity of employment found in the previous set of regressions (see HighTech columns in Table 1), which may be related to the impact of exchange rate movements on the price of imported inputs.

As for the destruction rate, the noticeable result is the negative effect that a depreciation has on employment destruction for very open (percentile 90) low-technology sectors: 
a 1 per cent depreciation decreases employment destruction by 3.8 per cent. This result reinforces the findings in previous estimates: exchange rate movements appear to have a larger impact on highly open low-technology sectors and this effect seems to occur through employment destruction. Job destruction in high-technology sectors seems to be immune to exchange rate movements. The inclusion of sectoral dummies makes the exchange rate elasticity for job destruction statistically insignificant, but does not change the sign, nor the economic significance, of the estimated elasticities.

The asymmetry of the response of job creation and job destruction to exchange rate variations is consistent with the idea that costs associated with firm size reductions might be smaller than the ones related with firm growth. This asymmetry may have welfare implications as decreases in job creation and increases in job destruction may carry very different costs for firms and workers. For example, in low-technology sectors, older and less skilled workers are more likely to be dismissed in the process of job destruction. This is an issue that deserves further research.

Finally, concerning reallocation (results reported in Alexandre et al., 2009a), the main result is the possibility that a depreciation may produce a 'chill' effect in the labour market, i.e., a reduction in job creation and destruction, and thus in job reallocation (see, e.g., Gourinchas, 1999). Namely, this may occur in the case of high-technology sectors with lower degrees of openness.

Table 2: Job creation and job destruction: OLS regressions in firstdifferences

\begin{tabular}{|c|c|c|c|c|c|c|c|c|}
\hline \multirow{3}{*}{ 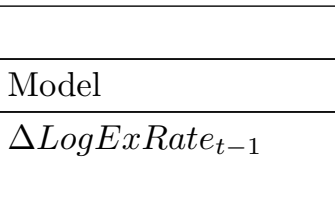 } & \multicolumn{4}{|c|}{ Job Creation } & \multicolumn{4}{|c|}{ Job Destruction } \\
\hline & \multicolumn{2}{|c|}{ HighTech } & \multicolumn{2}{|c|}{ LowTech } & \multicolumn{2}{|c|}{ HighTech } & \multicolumn{2}{|c|}{ LowTech } \\
\hline & $\begin{array}{r}-9.778^{* * *} \\
(3.031)\end{array}$ & $\begin{array}{r}-8.703^{* *} \\
(3.435)\end{array}$ & $\begin{array}{r}.384 \\
(.625)\end{array}$ & $\begin{array}{r}.598 \\
(.555)\end{array}$ & $\begin{array}{r}1.907 \\
(2.801)\end{array}$ & $\begin{array}{r}2.676 \\
(2.783)\end{array}$ & $\begin{array}{l}-1.486 \\
(2.179)\end{array}$ & $\begin{array}{l}-1.687 \\
(1.764)\end{array}$ \\
\hline$\Delta$ LogExRate E $_{-1} *$ Open & $\begin{array}{r}9.364^{* * *} \\
(2.944)\end{array}$ & $\begin{array}{r}8.470^{* * *} \\
(2.558)\end{array}$ & $\begin{array}{r}.540 \\
(1.802)\end{array}$ & $\begin{array}{r}.534 \\
(1.673)\end{array}$ & $\begin{array}{l}-2.140 \\
(2.647)\end{array}$ & $\begin{array}{l}-3.635 \\
(2.289)\end{array}$ & $\begin{array}{r}-3.270^{* * *} \\
(1.261)\end{array}$ & $\begin{array}{r}-1.395 \\
(.967)\end{array}$ \\
\hline$\Delta$ ShareImp $p_{t-1}$ & $\begin{array}{l}-.672 \\
(.718)\end{array}$ & $\begin{array}{r}-1.713^{* * *} \\
(.446)\end{array}$ & $\begin{array}{r}.089 \\
(.212)\end{array}$ & $\begin{array}{l}-.091 \\
(.238)\end{array}$ & $\begin{array}{l}1.018 \\
(.669)\end{array}$ & $\begin{array}{l}-.082 \\
(.487)\end{array}$ & $\begin{array}{r}.198 \\
(.144)\end{array}$ & $\begin{array}{l}.531^{*} \\
(.311)\end{array}$ \\
\hline Open $_{t-1}$ & $\begin{array}{r}.373^{* * *} \\
(.074)\end{array}$ & $\begin{array}{r}.335^{* * *} \\
(.083)\end{array}$ & $\begin{array}{r}-.048^{*} \\
(.026)\end{array}$ & $\begin{array}{l}-.004 \\
(.054)\end{array}$ & $\begin{array}{r}.036 \\
(.045)\end{array}$ & $\begin{array}{l}-.065 \\
(.095)\end{array}$ & $\begin{array}{l}-.046 \\
(.050)\end{array}$ & $\begin{array}{r}-.345^{* * *} \\
(.063)\end{array}$ \\
\hline \multirow[t]{3}{*}{ Sectoral dummies } & no & yes & no & yes & no & yes & no & yes \\
\hline & \multicolumn{8}{|c|}{ Exchange Rate Job Creation and Job Destruction Elasticities } \\
\hline & \multicolumn{8}{|c|}{ Percentile 10} \\
\hline HighTech Elasticity & $-7.464^{* *}$ & $-6.610^{*}$ & & & 1.378 & 1.778 & & \\
\hline \multirow[t]{2}{*}{ LowTech Elasticity } & & & .517 & .729 & & & -2.294 & -2.031 \\
\hline & \multicolumn{8}{|c|}{ Percentile 50} \\
\hline HighTech Elasticity & $-5.295^{* *}$ & -4.647 & & & .882 & .936 & & \\
\hline
\end{tabular}


.. table 2 continued

\begin{tabular}{|c|c|c|c|c|c|c|c|c|}
\hline \multirow{3}{*}{$\begin{array}{l}\text { Model } \\
\text { LowTech Elasticity }\end{array}$} & \multicolumn{4}{|c|}{ Job Creation } & \multicolumn{4}{|c|}{ Job Destruction } \\
\hline & \multicolumn{2}{|c|}{ HighTech } & \multicolumn{2}{|c|}{ LowTech } & \multicolumn{2}{|c|}{ HighTech } & \multicolumn{2}{|c|}{ LowTech } \\
\hline & & & .642 & .853 & & & -3.052 & -2.355 \\
\hline & \multicolumn{8}{|c|}{ Percentile 90} \\
\hline HighTech Elasticity & $-3.210^{* *}$ & -2.762 & & & .406 & .126 & & \\
\hline LowTech Elasticity & & & .763 & .972 & & & $-3.780^{*}$ & -2.665 \\
\hline Observations & 162 & 162 & 198 & 198 & 162 & 162 & 198 & 198 \\
\hline$R^{2}$ & .357 & .436 & .307 & .400 & .236 & .349 & .248 & .372 \\
\hline RMSE & .058 & .056 & .029 & .027 & .055 & .052 & .064 & .060 \\
\hline
\end{tabular}

Notes: Significance levels: $*: 10 \% \quad * *: 5 \% \quad * * *: 1 \%$. The dependent variable in each model is either job creation or job destruction as defined by the header in the section of the Table. All regressions are estimated by OLS, and include time dummies. RMSE is root mean squared error. The exchange rate is the average import/export exchange rate.

\section{Conclusion}

Several studies have shown that the degree of openness is an important determinant of the impact of exchange rate movements on labour markets. More recent theoretical and empirical work has highlighted instead the role of productivity. The contribution of this paper is to show that both these variables matter in the determination of the exchange rate elasticity of employment. Therefore, in order to capture the effect of exchange rate changes in employment and job flows, we estimated a model (using Portuguese data) that includes both a measure of openness and a measure of productivity, interacted with the exchange rate. Our estimates suggest that low-technology sectors very exposed to international competition suffer the most from exchange rate changes. Estimations using job flows suggest that the impact of exchange rates on these sectors occurs through employment destruction. On the contrary, high-technology sectors seem to be insensitive to exchange rate shocks.

Additionally, the estimated elasticities are larger than those estimated for more advanced economies. The higher elasticities found for the Portuguese economy may be a consequence of using the OECD technology classification to group industries. This classification may not capture idiosyncratic features of a sector in a particular country that may impact on that sector's exposure to external shocks. This is an issue that deserves further research. 


\section{References}

Alexandre, F., P. Bação, J. Cerejeira and M. Portela (2009a). Employment and exchange rates: the role of openness and technology. IZA Discussion Paper No. 4191. Institute for the Study of Labor, Bonn.

Alexandre, F., P. Bação, J. Cerejeira and M. Portela (2009b). Aggregate and sectorspecific exchange rates for the Portuguese economy. Notas Económicas, 30.

Alexandre, F., P. Bação, J. Cerejeira and M. Portela (2010). Employment, exchange rates and labour market rigidities. IZA Discussion Paper, No. 4891, IZA - Institute for the Study of Labour, Bonn.

Amador, J., S. Cabral and L.D. Opromolla (2009). A portrait of Portuguese international trade. In Banco de Portugal, The Portuguese Economy in the Context of Economic, Financial and Monetary Integration. Banco de Portugal, Lisboa, 2009.

Auer, R. and A. Fischer (2008). The effect of trade with low-income countries on U.S. industry. CEPR Discussion Paper Series \# 6819. Centre for Economic Policy Research.

Berman, N., P. Martin and T. Mayer (2009). How do different exporters react to exchange rate changes? Theory, empirics and aggregate implications. CEPR Discussion Paper Series No. 7493. Centre for Economic Policy Research.

Bernard, A., J.B. Jensen and P.K. Schott (2006). Survival of the best fit: exposure to low-wage countries and the (uneven) growth of U.S. manufacturing plants. Journal of International Economics, 86(1), 219-237.

Bound, J. and G. Johnson (1992). Changes in the Structure of Wages in the 1980's: An Evaluation of Alternative Explanations. American Economic Review, 82(3), 371-392.

Branson, W. and J. Love (1988). U.S. manufacturing and the real exchange rate. In R. Marston, ed., Misalignments of exchange rates: effects on trade and industry. Chicago University Press.

Burgess, S. and M.K. Knetter (1998). An international comparison of employment adjustment to exchange rate fluctuations. Review of International Economics, 6 (1), $151-163$.

Campa, J. and L. Goldberg (2001). Employment versus wage adjustment and the US dollar. Review of Economics and Statistics, 83 (3), 477-489.

Davis, S., J.C. Haltiwanger and S. Schuh (1996). Job creation and destruction. MIT Press, Cambridge, Massachusetts. 
Ekholm, K., A. Moxnes and K.H. Ulltveit-Moe (2008). Manufacturing restructuring and the role of real exchange rate shocks: a firm level analysis. CEPR Discussion paper no. 6904 .

European Comission (2008). Euro @ 10. Brussels.

Feenstra, R. (1989). Symmetric pass-through of tariff and exchange rates under imperfect competition: an empirical test. Journal of International Economics. February, 27, 2545.

Goldberg, L. (2004). Industry-specific exchange rates for the United States. Federal Reserve Bank of New York Economic Policy Review, May.

Gourinchas, P. (1998). Exchange Rates and Jobs: What do we Learn from Job Flows? In NBER Macroeconomics Annual, B. Bernanke and J. Rotemberg eds. The MIT Press.

Gourinchas, P. (1999). Exchange rates do matter: French job reallocation and exchange rate turbulence, 1984-1992. European Economic Review, 43, 1279-1316.

Klein, M.K., S. Schuh and R. Triest (2003a). Job creation, job destruction, and the real exchange rate. Journal of International Economics, 59, 239-265.

Klein, M.K., S. Schuh and R. Triest (2003b). Job creation, job destruction and international competition. Kalamazoo, Mich.: Upjohn Institute for Employment Research.

Lains, P. (2008). The Portuguese Economy in the Irish Mirror. Open Economies Review, $19(5), 667-683$.

Lopes, Silva (2008). Introduction, In Franco, Francesco, org., Challenges Ahead for the Portuguese Economy. Imprensa de Ciências Sociais, Lisboa.

Machin, S. and J. Van Reenen (1998). Technology and changes in the skill structure: evidence from seven OECD countries. Quarterly Journal of Economics, 113(4), 12151244 .

Melitz, M.J. (2003). The impact of trade on intra-industry reallocations and aggregate industry productivity. Econometrica. 71(6), 1695-1725.

OECD (2005). OECD Science, Technology and Industry Scoreboard, Annex 1, OECD.

Portugal. Ministry of Social Security and Employment (MSSE) (1988-2006). Quadros de Pessoal. Data in magnetic media.

Ravn, Morten O. and H. Uhlig (2002). On adjusting the Hodrick-Prescott filter for the frequency of observations. Review of Economic and Statistics, 84, 2, 371-376.

Revenga, A.L. (1992). The impact of import competition on employment and wages in U.S. manufacturing. Quarterly Journal of Economics. 107 (1), 255-284. 
Wood, A. (1994). North-South Trade, Employment and Inequality: Changing Fortunes in a Skill-Driven World. Oxford: Clarendon Press.

Wood, A. (1998). Globalisation and the Rise in Labour Market Inequalities. Economic Journal. 108, 1453-82.

\section{Appendix}

Table 3: List of Sectors

\begin{tabular}{ll}
\hline \hline Sector & LSIC Rev. 3 \\
\hline \multicolumn{2}{c}{ Low and medium-low technology sectors } \\
\hline food products, beverages and tobacco & $15-16$ \\
textiles, textile products, leather and footwear & $17-19$ \\
wood and products of wood and cork & 20 \\
pulp, paper, paper products, printing and publishing & 21 - 22 \\
rubber and plastics products & 25 \\
other non-metallic mineral products & 26 \\
iron and steel & $271+2731$ \\
non-ferrous metals & $272+2732$ \\
fabricated metal products, except machinery and equipment & 28 \\
building and repairing of ships and boats & 351 \\
manufacturing nec & $36-37$ \\
\hline \hline & \\
\hline \multicolumn{1}{c}{ High and medium-high technology sectors } & \\
chemicals excluding pharmaceuticals & 24, excl. 2423 \\
pharmaceuticals & 2423 \\
machinery and equipment, nec & 29 \\
office, accounting and computing machinery & 30 \\
electrical machinery and apparatus, nec & 31 \\
radio, television and communication equipment & 32 \\
medical, precision and optical instruments, watches and clocks & 33 \\
motor vehicles, trailers and semi-trailers & 34 \\
railroad equipment and transport equipment nec & $352+359$ \\
\hline
\end{tabular}


Table 4: Summary statistics

\begin{tabular}{|c|c|c|c|c|c|}
\hline Variable & Mean & Std. Dev. & Min. & Max. & $\overline{\mathrm{N}}$ \\
\hline$\Delta$ LogEmployment $t_{t-1}$ & -0.009 & $(0.110)$ & -0.621 & 0.548 & 360 \\
\hline$C 1$ & 0.100 & $(0.055)$ & 0.012 & 0.537 & 360 \\
\hline$D 1$ & 0.112 & $(0.066)$ & 0.021 & 0.848 & 360 \\
\hline$\Delta \log E x$ Rate $_{t-1}$ & -0.015 & $(0.016)$ & -0.052 & 0.010 & 340 \\
\hline Open $_{t-1}$ & 0.482 & $(0.186)$ & 0.168 & 0.956 & 360 \\
\hline$\Delta$ ShareImp $p_{t-1}$ & 0.009 & $(0.015)$ & -0.068 & 0.073 & 340 \\
\hline
\end{tabular}

